\title{
As éticas nas práticas de atenção psicológica na assistência social
}

\author{
Ethics in psyschologists' care practices \\ in social assistance fields
}

Silvio José BENELLI ${ }^{1}$

\section{Resumo}

Parte-se de diferentes modalidades de ética - da tutela, da interlocução, da ação social, do cuidado e da escuta do sujeito do desejo inconsciente -, como analisadores das práticas de atenção realizadas pelos psicólogos no âmbito da Assistência Social. Numa abordagem institucional, apresentam-se, de modo problematizador, casos, encontrados na literatura, considerados exemplares das práticas desenvolvidas por psicólogos e também por outros trabalhadores que atuam em estabelecimentos assistenciais os mais diversos. Conclui-se que os psicólogos podem encontrar, na psicanálise do campo de Freud e de Lacan, consistentes instrumentais teórico-técnicos e ético-políticos para orientar de modo efetivo e avisado uma atuação institucional que inclua o indivíduo como cidadão e também como sujeito do inconsciente.

Palavras-chave: Assistência social; Ética; Políticas públicas; Práticas (Psicologia); Psicanálise.

\begin{abstract}
This study presents different modalities of ethics - guardianship, interlocution, social action, care and finally the ethics of listening to the subject's unconscious desire - as analyzers of the care practices conducted by psychologists in the field of Social Assistance. In an institutional approach, cases found in the literature are presented, in a questioning way, which can be considered examples of the practices performed by psychologists and other workers who operate in a wide variety of healthcare establishments. It was concluded that psychologists may encounter, in the field of Freudian/Lacanian psychoanalysis, consistent theoretical-technical and ethical-political instrumentals to guide institutional performance in an effective and informed way so as to include the individual as a citizen and also as the subject of the unconscious.
\end{abstract}

Keywords: Social assistance; Ethics; Public policies; Practice (Psychology); Psychoanalysis.

Tomando por base em uma ampla literatura, este artigo apresenta um conjunto de reflexões sobre as possibilidades éticas que podem ser encontradas nas práticas profissionais realizadas por psicólogos - dentre outros trabalhadores -, no âmbito da Assistência Social, com base numa perspectiva institucionalista (Baremblitt, 1998; Barus-Michel, 2004; Lourau, 1995; Martins, 2002).

$\nabla \nabla \nabla$

1 Universidade Estadual Paulista Júlio de Mesquita Filho, Departamento de Psicologia Clínica, Programa de Pós-Graduação em Psicologia. Av. Dom Antonio, 2100, Parque Universitário, 19806-900, Assis, SP, Brasil. E-mail: <benelli@assis.unesp.br>. 
Partiu-se de uma questão fundamental como analisador: quais seriam os sentidos éticos e o estatuto dos efeitos das práticas institucionais com os quais os trabalhadores operam na Assistência Social? Esse é um tema pouco problematizado nos estabelecimentos institucionais que oferecem programas, projetos e os variados serviços socioassistenciais. Entretanto, mesmo que os diversos atores institucionais não se perguntem pelos efeitos de suas práticas, nem por isso tais efeitos deixam de se produzir. No melhor dos casos, deles também se poderia dizer: se não sabem o que fazem, suas práticas muitas vezes podem seguir lógicas paradigmáticas diversas que também produzem efeitos vários, muitas vezes contrariando suas intenções conscientes (Benelli \& Costa-Rosa, 2011, 2012, 2013). Também não se desconhece que, infelizmente, nessa área profissional, pode haver cinismo e má-fé, o que realmente implicará atuações que permanecerão abaixo da crítica, dado seu amadorismo ateórico, seus procedimentos caseiros baseados no senso comum - quando não no preconceito -, e suas estratégias improvisadoras, ingênuas e desimplicadas. Se, por um lado, Foucault (1995, p.206) afirma que "as pessoas sabem aquilo que elas fazem; frequentemente sabem por que fazem o que fazem; mas o que ignoram é o efeito produzido por aquilo que fazem"; por outro, a psicanálise do campo de Freud e Lacan há muito ensina que as ações realizadas e as palavras proferidas, quando se dirigem ao semelhante, como injunções, podem produzir efeitos bem mais amplos do que poderiam supor os trabalhadores em suas intenções iniciais (Julien, 1996). Considera-se que tanto as práticas quanto os discursos são produtores de determinados efeitos éticos.

Na análise empreendida no presente artigo, trabalha-se com a hipótese de que os paradigmas assistenciais mapeados por Benelli e Costa-Rosa $(2011$; 2012; 2013) podem ser orientados por diferentes possibilidades éticas, que podem ser nomeadas como sendo a ética da tutela, a ética da interlocução, a ética da ação social (Freire Costa, 1996) e a ética do cuidado (Ferreira, 2000). Como possibilidade de subversão dessas modalidades, 270 indica-se a ética do sujeito do inconsciente, ser de linguagem e de desejo: a ética da Atenção Psicossocial (Costa-Rosa, 2011a). Contudo, não se pretende afirmar que necessariamente essas práticas promotoras de determinados efeitos éticos sejam realizadas por pessoas que têm essa intenção deliberada, numa crítica ingênua, culpabilizadora e moralista dirigida aos profissionais. É possível que eles não consigam calcular os efeitos das práticas que implementam, nem visem conscientemente a esse fim; entretanto, esse parece ser um dos sentidos importantes de sua produção geral, de acordo com nossas análises, tanto a partir da literatura quanto de uma inserção prolongada no campo como docente, supervisor de estágio de alunos da graduação em Psicologia e pesquisador.

Desde logo, as considerações apresentadas sobre a ética não partem de questões filosóficas gerais. No entanto, é importante distinguir claramente entre ética e moral, pois se é consciente de que esta, de um modo geral, atravessa os modelos de ética que são discutidos. A moral consiste num conjunto de valores concernentes ao bem e ao mal, ao proibido e ao permitido e à conduta correta e à incorreta, válidos para todos os membros de uma dada sociedade. A simples existência da moral não implica explicitamente uma ética, que seria uma problematização filosófica, racional e sistemática, sobre as noções, os princípios e os significados dos valores que fundamentam a vida moral. Posto isso, buscou-se inspiração num conjunto de trabalhos que foram produzidos no campo denominado Atenção Psicossocial no campo da Saúde Mental Coletiva (Abreu Filho, 1996; Costa-Rosa, 2011 b; Ferreira, 2000; Freire Costa, 1996; Gondar, 2004; Julien, 1996). Procurou-se seguir a hipótese de Costa-Rosa (2011b, p.756), de que "esse conjunto de proposições pode ser desdobrado nas situações de outras demandas do campo social e institucional, e para outros intercessores e outros processos de intercessão, além das clínicas psi". As homologias entre os campos das Ciências Humanas, tais como a Psicologia, a Sociologia, a Pedagogia, o Serviço Social e as Ciências Médicas Psiquiátricas, são dadas pelo marco disciplinar que caracteriza esse conjunto de saberes e de poderes, historicamente constituídos (Foucault, 1999). 
Com base nos trabalhos referenciados, será apresentada uma síntese das quatro modalidades éticas já indicadas, e, ao mesmo tempo, uma discussão na qual se pretende caracterizar as possibilidades éticas de diversos paradigmas de produção de realidade social - e certamente também subjetiva -, que podem ser encontrados na Pedagogia, na Psicologia e na Sociologia, que incidem no campo institucional da Assistência Social. Na literatura, também podem ser encontradas indicações da pregnância dessas possibilidades no campo social concreto, no qual se inserem os psicólogos, tanto na Assistência Social quanto nas áreas da Saúde, incluindo a Saúde Mental, e na Educação. A ética do sujeito tal como postulada a partir da psicanálise do campo de Freud e Lacan também será apresentada. Postula-se que a dimensão subjetiva, para além de qualquer ideia de interioridade psicológica privatizada, não se esgota no plano social nem sequer em práticas pautadas na sociologização ou politização dos impasses psíquicos do sujeito.

\section{Caracterizando as diferentes modalidades éticas como instrumental analítico}

Freire Costa (1996, p.27) apresenta uma discussão relativa ao que denomina como sendo as "éticas da psiquiatria". Ele indica que se trata de uma formulação sobre três "tipos ideais" de ética, presentes na assistência realizada na prática psiquiátrica. Certamente, tais modelos não se apresentam de modo puro na realidade, pois são apenas constructos teóricos que servem para pensar aspectos da realidade, tratando-a de modo conceitual. Também é importante indicar que a psiquiatria, como profissão médica e como lógica de ação, antecede historicamente o campo da Atenção Psicossocial e não se confunde com ele (Costa-Rosa, 2011a; Yasui, 1999, 2010), embora possa nele se inserir. Considerando as possibilidades e os limites da ética da tutela, da interlocução e da ação social, Freire Costa (1996, p.27) postula uma ética do sofrimento, cuja máxima consiste em jamais realizar algo que "atente contra a integridade física e moral do seu semelhante". Parece que ele já estaria apontando para a ética do cuidado, que ressoa como uma versão cristianizada inspirada nas práticas da caridade. Afirma ainda que, dentre as éticas disponíveis, caberia escolher - de acordo com as circunstâncias -, a melhor delas, o que representaria uma escolha, portanto, meramente pragmática. Entretanto, esse critério não parece suficiente.

As práticas sociais em geral podem ser consideradas como tecnologias sociais, pois são frutos do trabalho coletivo e social humano. Além delas, há ainda as tecnologias que criam e utilizam máquinas, aparelhos mecânicos, eletrônicos e informáticos. Há o costume de pensar em tecnologia apenas quando se trata de máquinas e equipamentos sofisticados e complexos, sobretudo quando são caros, custosos. Equipamentos, estabelecimentos institucionais, atores, saberes e técnicas compõem tecnologias sociais complexas. É preciso superar essa concepção simplista e pensar que as Ciências Humanas, as Ciências Sociais e as Ciências da Saúde são também tecnologias de alta densidade. A Psicologia, o Serviço Social, a Pedagogia, a Administração e o Direito são tecnologias sociais científicas e produtoras de realidade social. Portanto, trabalhos no campo das políticas públicas devem ser considerados como intervenções de alta densidade tecnológica, para além do amadorismo ateórico e da improvisação caseira, pois eles exigem conhecimentos, habilidades e práticas de alta complexidade para lidar com problemas complexos que não podem ser equacionados a partir de compreensões superficiais, funcionalistas e monocausais. Normalmente, os problemas com os quais lidam os profissionais que atuam nas políticas públicas exigem abordagem transversal e transdisciplinar e trânsito pelos planos da política, da economia, da administração pública, da Saúde, da Assistência Social, da Educação, da Segurança Pública e do Judiciário, das Ciências Sociais e Humanas.

Considera-se que o trabalho dos profissionais no âmbito da Assistência Social utiliza tecnologia social de elevada complexidade e baixa densidade, uma vez que a atuação nos equipamentos assistenciais não se caracteriza por um conjunto de ações e de procedimentos simples, como se costuma supor. Ao contrário: uma atuação efetiva nesse contexto deve partir da premissa de 
que as ações a serem realizadas no território são de alta complexidade e que, portanto, exigem abordagens pautadas em alta densidade tecnológica. Tal complexidade advém do próprio trabalho coletivo, por um lado, pois um trabalho coletivizado não deixa de ser complexo; por outro lado, é preciso notar que os problemas relacionados com a questão pobreza-cidadania estão atravessados por uma diversidade de fatores determinantes dos processos de exclusão-exploração-marginalização que o capitalismo globalizado inflige aos brasileiros pertencentes às classes populares em geral.

As tecnologias utilizadas no trabalho profissional na Assistência Social podem ser consideradas de média densidade, pois contam com aparelhos e procedimentos sofisticados, por exemplo, que envolvem computadores, manuseio de programas, conexões por meio da Internet etc. Entretanto, nesse trabalho, é utilizado basicamente e prioritariamente o que se denomina de tecnologias relacionais ou, como chamou Merhy (1998, p.103), tecnologias leves e tecnologias leveduras. Essa terminologia é típica da área da saúde e é útil para diferenciar as tecnologias utilizadas nessa política pública, referindo-se às que fazem uso especificamente da relação e do vínculo entre os indivíduos de tecnologias leves. A tecnologia que, além da relação, utiliza-se de um conhecimento construído a partir de determinado núcleo de conhecimentos foi denominada tecnologia leveduras, e a tecnologia que consiste basicamente em procedimentos com uso de máquinas e equipamentos ou ainda exames, de tecnologia dura (Merhy, 1998). Contudo, ressalte-se de antemão que os termos relacional, relação e vínculo também são utilizados normalmente no campo da Psicologia, de modo a se permanecer apenas no plano da consciência e das relações interpessoais, ignorando o plano do inconsciente e a dimensão da transferência, na acepção específica postulada pela Psicanálise de Freud e Lacan, que são considerados essenciais nessa discussão, pois preza-se pela produção de subjetividade singularizada e que se autogere.

Interessa discutir uma ética na qual o homem 272 possa ocupar o lugar de sujeito em sua singula- ridade. Em sentido amplo e comum, o sujeito pode designar apenas o ego cognoscente - o eu centrado na consciência racional e reflexiva, no plano da epistemologia tradicional. A consciência racional seria supostamente passível de educação, de formação crítica e de politização. O sujeito também pode ser o homem como ator social e indivíduo agente, pessoa autônoma e cidadão protagonista na ordem da política. No entanto, essa definição que se considera valiosa e um bom ponto de partida para a discussão - e menos do que isso já parece criticável -, ainda não contempla a dimensão da subjetividade numa acepção precisa que incluiu fundamentalmente a noção de inconsciente, tal como postulada no campo de Freud e Lacan. Porém, fundamentalmente, a concepção de sujeito inclui as noções de sujeito do inconsciente, de sujeito dividido e de sujeito de desejo (Cabas, 2009; Fink, 1998), segundo as quais o ego ou o eu não cobre a totalidade do sujeito (Vallejo \& Magalhães, 1979, p.158). Se não se avança no plano da especificidade subjetiva do homem, ser de linguagem e de desejo inconsciente, corre-se sempre o risco, de um modo ou de outro, de tomá-lo como objeto. E também se entende que, se não houver implicação subjetiva, tampouco haverá implicação sociocultural transformadora (Costa-Rosa, 2000; 2011a; 2011b).

\section{A ética da tutela}

Um primeiro modelo pode ser intitulado como ética da tutela (Freire Costa, 1996). Nele, o agente da atenção em saúde dirige-se ao outro como um indivíduo que é tratado a partir de uma posição prévia, embasado na racionalidade científica. É a partir dos conhecimentos científicos e médico-psiquiátricos que o trabalhador apreende o indivíduo como um conjunto de informações físicas, corporais e orgânicas que estariam na origem do seu mal-estar e que seriam as responsáveis pela privação do exercício pleno da razão que o indivíduo sofredor apresenta (Clavreul, 1983). Ao concebê-lo dessa forma, o médico priva o indivíduo de razão e vontade, objetificando-o, tomando-o como objeto passivo da sua intervenção de mestria (Lacan, 1992). É o profissional que sabe pelo outro que sofre, sabe 
sobre o que o faz padecer; o outro é tido como sendo incapaz de dizer de si e de sustentar-se adequadamente na vida social. A partir dessa postura, desliza-se rapidamente para um conjunto de ações e práticas jurídico-legais que, como consequência, promovem efeitos tuteladores sobre o indivíduo (Benelli \& Costa-Rosa, 2003, 2011; Costa-Rosa, 2011a; Goffman, 1987). Nessa concepção de 'cuidado' médico, há reduzido espaço para o questionamento do plano social e institucional instituído, sedimentada que está nos especialismos e nas pesquisas em cascata que retroalimentam suas práticas e o conjunto de valores que a emolduram. Trata-se, portanto, de uma ética que lida com o outro como se ele fosse apenas mais um objeto qualquer da natureza, com vistas a conhecê-lo para poder prever e assim controlá-lo melhor. Uma razão instrumental, científica e médica adota coerentemente uma ética também instrumental, promotora de reclusão asilar (Ferreira, 2000).

Não se pode deixar de notar que a ética da tutela também parece presidir as práticas da Pedagogia e da Educação, da Psicologia, do Serviço Social e de suas práticas de assistência. Talvez fosse possível considerar inclusive que essa ética seja hegemônica no conjunto das Ciências Humanas disciplinares (Foucault, 1999). No campo da Educação, o Paradigma da Pedagogia Tradicional e autoritária, tal como descrito por Cotrim (1993), Saviani (1988); Libaneo (1994), Coll, Marchesi e Palácios (2004) e por Francisco Filho (2004), discutido e problematizado por Benelli (2012), parece bem alinhado com a ética da tutela. Na área da Psicologia e das psicoterapias orientadas por essa ética, poderiam ser incluídas as práticas psicométricas (Patto, 1997), os testes psicológicos, as psicoterapias do ego ou da consciência (Baratto \& Aguiar, 2007), sendo que tais saberes e práticas se enquadram na Psicologia Tradicional, de viés psicologizante, terapeutizante e patologizante do indivíduo. Nessa vertente, a Psicologia busca trabalhar com um objeto que tem recebido diversas denominações ao longo do tempo: sujeito da consciência, caráter, personalidade, identidade, ego racional, conduta, comportamento (Bernandes, 2007). O indivíduo é considerado portador de uma interioridade psicológica, de um espaço psíquico que se desenvolve de modo endógeno, a partir de possibilidades orgânicas inatas. Seus desvios devem ser tecnicamente corrigidos conforme a norma social.

No âmbito da Assistência Social, com base no mapeamento realizado por Benelli e Costa-Rosa (2012), os paradigmas da Filantropia e do Clientelismo Assistencialista do poder público apresentam notáveis características dessa ética tuteladora e autoritária. A Assistência Social como Política de Estado está formalmente garantida pela Constituição Federal (Brasil, 1988), pela Lei Orgânica de Assistência Social (LOAS) (Brasil, 1993, 2011), pelo Programa Nacional de Assistência Social (PNAS) (Brasil, 2004), pelo Sistema Único Assistência Social (SUAS) (Brasil, 2005, 2012). Contudo, de acordo com Benelli e Costa-Rosa (2011, 2012), ela tende a permanecer num plano retórico, e parece se tratar de um discurso arrojado com objetivos mais simbólicos do que práticos, pois não prevê orçamento público efetivo e suficiente para sua consecução. Os indícios mais claros levam a concluir que ela visa legitimar a hegemonia da ordem social vigente, mais do que promover sua transformação. O discurso oficial afirma que pretende promover o atendimento dos direitos sociais individuais como dever do Estado e da sociedade, visando à erradicação da pobreza, mas se observa que ele continua sendo permeado por uma visão naturalizante dos problemas sociais e do fenômeno da pobreza. Não se nota qualquer ensaio de aprofundamento da análise crítica da produção histórica e social da miséria e da pobreza pelo modo capitalista de produção na realidade brasileira. Seus efeitos assistenciais e éticos apontam para a manutenção da ordem por meio da integração tuteladora e da inclusão consentida, esvaziando a capacidade de organização, de luta e reivindicação dos movimentos sociais populares, ao assumir e encampar alguns de seus temas como parte dos programas de governo, mas sem promover mais do que atividades focalizadas de impacto simbólico e publicitário, com objetivos eleitoreiros.

A sociologia funcionalista também pode ser pensada como produtora de efeitos éticos tuteladores. Não é incomum que análises simplistas e 
simplificadoras, que se pautam pela noção linear de causa-efeito, postulem a existência de problemas específicos simples, desconectados e descontextualizados da globalidade social complexa - em suas múltiplas dimensões históricas, culturais, econômicas, políticas e psíquicas -, que, uma vez detectados, circunscritos, compreendidos e explicados, seriam passíveis de solução com o emprego e a utilização de medidas simples. Essa perspectiva tende a operar com a noção de marginalidade, de desvio patológico e de disfunção social, e propõe ações de "integração social", de ressocialização, de reinserção social.

Na literatura, encontram-se algumas pesquisas (Araújo, 2010; Cruz, 2009; Oliveira, Dantas, Solon, \& Amorim, 2011) que revelam a permanência dessa possibilidade ética ao se investigarem as práticas que os psicólogos desenvolvem no campo da Assistência Social. Evidentemente, não é uma perspectiva que os trabalhadores proponham de modo claro e intencional, mas ela pode ser inferida e deduzida a partir das práticas relatadas como práticas marcadas por uma evidente ausência de embasamento teórico, podendo ser localizadas no plano do senso comum, na improvisação e no amadorismo. Isso certamente depõe contra o profissionalismo e a ética da Psicologia, tanto como ciência quanto como profissão, deixando clara a baixa qualidade da formação de muitos psicólogos diplomados.

\section{A ética da interlocução}

Na ética da interlocução (Freire Costa, 1996), tanto o agente quanto o indivíduo são definidos a partir do vocabulário psicológico tradicional; trata-se, portanto, de dois sujeitos ou pessoas em diálogo, estando ambos localizados no plano da relação intersubjetiva igualitária: eu e o outro, eu e tu, eu e o semelhante. Segundo Ferreira (2000), essa seria $\simeq \quad$ a ética da moral privada. Nota-se que se trata de uma versão meramente alternativa da anterior. Nesse caso, o agente da ação vê o outro como "portador de outra vontade e de outra razão" (p.140), no entanto, apesar dessa diversidade, percebe-o 274 como sendo competente e, por meio do diálogo, pode chegar, com auxílio e orientação do agente, a encontrar algumas soluções para seus impasses e dificuldades. A insígnia de saber do especialista está lá, mas o outro detém o poder decisório e a capacidade de escolha racional. Essa vertente ética se fundamentaria no plano da moral privada da pessoa, em sua dignidade de pessoa capaz de um comportamento moral e racional adequado. Essa ética seria dotada de força de contestação do instituído e também de geração do novo, mas, como se baseia primeiramente na transformação pessoal do indivíduo, perde força ao tentar realizar modificações no contexto social mais amplo. Essa ética do diálogo intersubjetivo entre pessoas iguais subjaz a todo um conjunto de dispositivos supostamente inspirados na psicanálise, mas que em geral não reconhecem nela suas origens, podendo ser encontrada em inúmeras modalidades de psicoterapias realizadas tanto em consultórios privados quanto em ambulatórios públicos, assim como nas estratégias de autoajuda (Benelli, 2009; Depraz, 2005).

Na Assistência Social, o paradigma da promoção humana descrito por Benelli e Costa-Rosa (2012) poderia ser localizado nessa perspectiva ética. A técnica pedagógica é renovada e de matiz mais psicologizante, centrando-se no indivíduo que aprende, e não mais no educador que ensina. Também se caracteriza ainda por um acentuado voluntarismo, partindo do princípio de que os indivíduos são livres e capazes de adotar crenças e outras atitudes de acordo com sua própria vontade, desconsiderando os determinantes históricos, sociais e subjetivos que incidem na produção da vida social. $\mathrm{Na}$ dimensão sociológica, observa-se que essa é a ética do liberalismo: o homem é entendido como um indivíduo dotado de uma natureza humana universal, racional. Ele seria formal e juridicamente igual aos seus semelhantes, devendo as diferenças étnicas e culturais ser incluídas no plano privado, numa moral particular e pessoal. Seria essencialmente dotado de liberdade pessoal e social, senhor de si e também da posse de bens e de propriedades particulares, das quais poderia fazer o que bem entendesse.

Encontra-se na literatura um artigo (Lima \& Cerveny, 2012) que parece exemplar dessa moda- 
lidade ética, caracterizado por um viés surpreendentemente eclético: os autores mesclam conceitos da área da Psicologia Organizacional, do pensamento sistêmico novo paradigmático, apresentam uma concepção cognitivista do homem (ser de pensamento, de habilidades e de atitudes) e uma adesão ingênua ao tema da pós-modernidade. Ficam presos nas aporias da relação indivíduo-sociedade e do psiquicossocial, o que se depreende a partir dos termos que empregam, tais como interconstituição, intrapsíquico, interpsíquico, intersubjetividade. Sua dificuldade em operar de modo sistêmico e dialético parece reveladora do seu funcionalismo. O cidadão tornou-se cliente, a subjetividade seria sinônimo de fenômenos relacionais e o indivíduo seria um self processual e relacional. Sua concepção do que seria a clínica ampliada é ingênua e inclui o olhar, o intrapsíquico, a subjetividade relacional, o interpsíquico, um viés da pedagogia renovada humanista e dialogante. Parecem fazer certa apologia da improvisação e da ignorância no trabalho profissional dos psicólogos, como se a falta de clareza teórico-técnica e ético-política e a capacidade de criação e de invenção fossem equivalentes. Também empregam os termos ajuda, missão e ação social ao se referirem ao que orienta a prática dos psicólogos, o que é representativo da colagem que constitui sua argumentação. O trabalho do psicólogo parece reduzir-se a uma pedagogia terapêutica, a uma presença terapêutica, conselheira, moralizante, educativa, o que aparentemente também poderia fazer qualquer indivíduo, com ou sem formação específica em Psicologia, tanto um educador social com ensino médio quanto um assistente social ou um professor de educação física, dentre outros. A Psicologia, e sobretudo uma Psicologia precavida por outros referenciais específicos, não dispõe de instrumentos teóricos, técnicos, políticos e éticos mais consistentes do que esses? Não há nenhuma especificidade no trabalho do psicólogo nas instituições?

A noção de conversação terapêutica dá a chave que permite localizar essa modalidade de atuação profissional situada no plano da consciência racional, no âmbito ego-realidade e na perspectiva carência-suprimento, alinhada com a adaptação e o ajustamento social. Lima e Cerveny (2012) concluem seu artigo afirmando que não há volta quanto às práticas da psicologia. Rosas (2010) também afirma que ... enquanto profissional, o psicólogo deve manipular técnicas, as quais, no seu caso, podem ser classificadas como de mensuração, diagnóstico, avaliação, orientação, psicoterápicas e persuasivas" (p.86). Numa perspectiva diametralmente oposta, postula-se a possibilidade da subversão dessas práticas adaptativas, alienantes e normalizadoras, a partir da questão da subjetividade e do sujeito, tais como formuladas por Freud e Lacan.

\section{A ética da ação social}

Na modalidade ética da ação social (Freire Costa, 1996), tanto o indivíduo quanto o agente da assistência estariam engajados em renovar o instituído, visando transformar a realidade na ordem sociopolítica, com base na defesa, recuperação e construção do estatuto de cidadão do sujeito que se encontra em sofrimento psíquico, para que ele conquiste e construa espaços de interação. Essa modalidade ética já aspira a uma alternatividade radical com relação à ética tuteladora disciplinar. Algumas das práticas pautadas por essa ética - tais como as ações políticas visando ao empoderamento social, ao aumento da capacidade de contratualidade social, à construção de possibilidades de circulação e de convivência no território - adquirem, por vezes, por si sós, virtudes, atributos e possibilidades terapêuticas. A ética pública é o seu modelo e nesse grupo podem ser incluídas as práticas da psiquiatria democrática italiana (Fleming, 1976; Rotelli, 1994), da antipsiquiatria (Gallio \& Constantino, 1993; Oury, 2009) e de profissionais psi focados no trabalho com as chamadas "minorias": mulheres, negros e marginalizados em geral. Ferreira (2000, p.148) qualifica tal ética como sendo focalizada em processos de reinserção social, mas, muitas vezes, pretende-se "reinserir" os pobres onde provavelmente eles nunca estiveram inseridos anteriormente.

A Pedagogia Dialética, Social e Crítica (Benelli, 2012; Cotrim, 1993; Coll et al., 2004; Francisco 
Filho, 2004; Libaneo, 1994; Saviani, 1988) indica claramente a ética da ação social. A educação Popular (Hurtado, 1992) também poderia ser incluída nessa modalidade ética. Rey $(2003,2004)$ e Furtado e Rey (2002), partindo da escola soviética de Psicologia criada por Vigotsky e por Rubinstein que se fundamentaram no marxismo como ponto de partida para a construção de uma psicologia científica dialética -, propõem as bases para o desenvolvimento de uma psicologia social crítica na perspectiva denominada histórico-cultural. Nessa linha, ainda há os trabalhos de Bock, Gonçalves e Furtado (2002); de Castro (2009) e de Alves (2010). Entretanto, o subjetivo e a subjetividade nesses autores ainda não incluem a concepção do inconsciente de Freud e Lacan, perman-cendo no plano da consciência (Gonçalves, 2010). No plano da sociologia, não se pode deixar de indicar que a perspectiva dialética é aquela que já contém a possibilidade de tratar o outro como sujeito, sobretudo como sujeito social protagonista, como agente transformador da história (Demo, 1987). Alguns dos limites dessa ética se localizam na centralidade da consciência racional, num certo ativismo político, no recorte de classe social, na crença idealista de que a ideologia pode ser eliminada por meio da informação e do acesso ao conhecimento, considerando-se que o conhecimento crítico seria capaz de promover a autonomia e a transformação social (Aguiar \& Rocha, 2007).

Pode-se considerar que são numerosos os trabalhos alinhados com o pensamento crítico, social e dialético, fomentador de práticas psicológicas de caráter marcadamente social e transformador (Costa \& Cardoso, 2010; Dadico \& Souza, 2010; Eidelwein, 2007; Gonçalves, 2010; Mauriel, 2010; Paiva, Rocha, \& Carraro, 2010; Paiva \& Yamamoto, 2010; Senra \& Guzzo, 2012; Silva \& Corgozinho, 2011; Ximenes, Paula, \& Barros, 2009; Yamamoto \& Oliveira, 2010). Essa literatura apresenta a atuação do psicólogo comprometido com a promoção de direitos, de cidadania, de saúde, com a promoção da vida, a partir do contexto no qual vive a população atendida. Em geral, propõe, a partir das intervenções dos profissionais da Psicologia, 276 atravessar o cotidiano de desigualdades e violências no qual vive a população, visando ao enfrentamento e à superação da exclusão social e da pobreza, investindo na apropriação, por todos, do lugar de protagonista na conquista e afirmação de direitos. É possível ver como essa modalidade ética se exemplifica em referências orientadoras da Psicologia para a atuação profissional.

\section{O paradigma do sujeito cidadão nas políticas públicas}

A Assistência Social como política de Estado parte de uma terminologia muito interessante e, aparentemente, bastante arrojada: opera com diversos significantes: sujeito de direitos, cidadão, protagonismo, cidadania, participação democrática, controle social (Brasil, 2004, 2005; Conselho Nacional de Assistência Social, 2009, 2011). A questão que se coloca é a seguinte: as atuais possibilidades paradigmáticas presentes e efetivas no campo, bem como seus efeitos éticos particulares, são capazes de construir o protagonismo do usuário - como sujeito cidadão de direitos da Assistência Social -, tal como pretende o discurso oficial que permeia essa política de Estado? Será que é possível promover o que se pode denominar de implicação sociocultural, no sentido de que os sujeitos possam atuar efetivamente como atores sociais na ordem da política - visando à construção de uma democracia radicalmente popular -, sem que haja também implicação subjetiva?

O poder disciplinar instituiu as ciências humanas, dentre elas a Psicologia e o Serviço Social, com as funções de vigiar, educar, tratar e punir, visando a um processo de normalização, de adaptação do indivíduo à sociedade. É possível notar que há conflitos, discordância e diferenças entre, por um lado, os interesses do sujeito cidadão e usuário, tanto dos serviços da Psicologia, do Serviço Social e da Assistência Social, e, por outro, os interesses do Estado, das classes dominantes, das autoridades municipais locais. O SUAS propõe o protagonismo do usuário como a questão central em torno da qual se estabelecem os princípios da territorialidade, da integralidade, da participação popular no planejamento, gestão e controle dos dispositivos e 
ações em Assistência Social. Isso significa que o indivíduo cidadão e sujeito é o protagonista da produção das respostas de sentido e de ações capazes de fazerem frente aos problemas com os quais se enfrenta. Tal protagonismo será exercido numa relação de intercessão com os trabalhadores da Assistência Social e talvez não possa ser feito sem eles, mas certamente poderá ser feito apesar e à revelia deles, quando sua ação profissional se orientar para a adaptação social, para a subserviência e a resignação social diante de uma (des)ordem social despótica e injusta.

Num plano de análise social e histórico, todo ser humano é sujeito de direitos e todo sujeito é, antes de tudo, produtor de saber e de conhecimento. No campo humano, todo conhecimento é autoconhecimento (Santos, 2000), mas é preciso considerar que, do ponto de vista da psicanálise, o homem, como cidadão e indivíduo social, é apenas um suporte para o sujeito do inconsciente, $e$, nesse caso, o conhecimento racional chega mesmo a ser dispensável, pois não se trata de conhecer, mas de analisar (como na química). Não é que se despreze o plano racional, mas importa que a consciência seja sensível e capaz de levar em consideração tanto o inconsciente quanto seus efeitos. Nesse sentido, é possível afirmar que "não há saber capaz de operar sobre os impasses do sujeito do inconsciente que não seja saber criado pelo próprio sujeito, ensinamento maior presente em praticamente todas as psicanálises" (Costa-Rosa, 2011a, p.275). O sujeito é quem possui os meios mais potentes para as saídas possíveis de seus impasses. Sendo assim, superar relações verticais como as que se dão entre supridores e carentes, assistidores e assistidos, sabedores e ignorantes, agentes e público-alvo passivo torna-se exigência radical da ética e da técnica dos psicólogos no âmbito da Assistência Social. Todos são cidadãos, todos são sujeitos de direitos e de deveres, todos são protagonistas da construção de direitos: tanto a equipe de profissionais quanto os sujeitos-usuários dos serviços, projetos e programas da Assistência Social. Práticas democráticas e dialogantes, participação, palavra circulante e organização coletiva são estratégias fundamentais. O agente principal do processo de transformação é o cidadão-sujeito, ele é o trabalhador da própria modificação de si e também da ação social transformadora. Ética, aqui, significa produção de sujeito autônomo, capaz de ação, agente, no plano do indivíduo como cidadão de direitos.

O discurso oficial da Psicologia (Crepop, 2008) tematiza qual seria o campo específico do psicólogo no âmbito da Assistência Social: ele atuaria no plano da experiência subjetiva do sujeito, sem adjetivá-la, sem defini-la ou explicitá-la. Aí caberia de tudo um pouco? Depois, o texto articula o significante campo simbólico, sem maiores precisões. Fala ainda de condições subjetivas, sem maior caracterização. Em outro lugar, esclarece que "... entende-se que a atuação dos(as) psicólogos(as) no SUAS deve estar fundamentada na compreensão da dimensão subjetiva dos fenômenos sociais e coletivos, sob diferentes enfoques teóricos e metodológicos, com o objetivo de problematizar e propor ações no âmbito social" (p.32). O psicólogo trabalharia então com o "fenômeno psicológico" (p.33), atento para sua "dimensão subjetiva". Não é difícil deduzir a influência importante da Psicologia Sócio-Histórica (Bock, Gonçalves, \& Furtado, 2002; Gonçalves, 2010) nesse documento, ficando bem claro nas suas referências (Crepop, 2008). Mas o que compreenderia, afinal, de um modo conceitual e rigoroso, essa questão nebulosa denominada de dimensão subjetiva? Curiosamente, o termo propriamente dito subjetividade não ocorre nenhuma vez nesse texto (Crepop, 2008). É até aí que chega esse interessante documento de referência para os psicólogos. Mas entende-se que é preciso avançar na discussão e nas bases conceituais e éticas que subsidiam práticas profissionais. É importante ter clareza quanto ao fato de que a ética do sujeito cidadão de direitos não coincide com a ética do sujeito do inconsciente (Rinaldi, 2006). Produzindo realidade social no sentido da judicialização da sociedade (Souza \& Prado Filho, 2008), no limite, ela poderia ser considerada como oposta à ética do sujeito do inconsciente. O que parece bastante interessante é a brecha discursiva que aí se abre, talvez mesmo que inadvertidamente.

A coerência lógica exige que esse termo seja tomado de modo adjetivado e teoricamente bem 
situado em torno do sujeito. Encontra-se, na Psicanálise de Freud e Lacan, uma teoria que demonstra como o sujeito e a realidade subjetiva se constituem e se processam no bojo mesmo da realidade social e histórica e, concomitantemente, constituem essa mesma realidade. Entendendo como os fenômenos psíquicos primários se constituem na sua processualidade complexa e específica, em seus múltiplos movimentos e vicissitudes, impasses e modalizações, o psicólogo poderia situar-se adequadamente na escuta, no trabalho clínico e social, buscando promover processos de subjetivação e de singularização que permitam o equacionamento tanto de impasses psíquicos quanto a emergências de transformações pessoais e sociais a partir da implicação subjetiva e sociocultural. Mas, antes de tratar dessa questão, será apresentada outra modalidade ética bastante problemática presente no campo.

\section{A ética do cuidado}

Ferreira (2000), ao discutir a ação no campo dos cuidados na Saúde Mental, propõe o que denomina de ética da compaixão, uma ética que se fundamenta numa empatia com o sofrimento do outro. Assim, o cuidador, ao se identificar com a dor do outro, torna-se solidário com ele, compadecendo-se do seu sofrimento. Trata-se de uma ética da empatia e da compaixão (Costa-Rosa, 2011b). Ele afirma que "cuidar do outro não significa submetê-lo aos nossos domínios, mas sim inclinar-se sobre alguém que vivencia a diversidade em seu próprio corpo e espírito. Isso exige uma dose de empatia e também de sofrimento" (p.150).

Embora Ferreira (2000), ao discutir a ética do cuidado, busque se fundamentar numa perspectiva psicanalítica, curiosamente acaba por enveredar pelo campo da moral e, ao querer superar a frieza técnica do trabalhador ao lidar com o outro, parece deslizar para o plano da ajuda ao próximo, que fundamenta a ética cristã. Ora, cuidar do outro consiste ainda em colocá-lo no lugar e na posição de objeto, não de sujeito. Observa-se que esse tipo de cuidado assemelha-se muito à ética da tutela, apesar da terminologia diferenciada. Costa-Rosa (2011b), ao analisar criticamente a modalidade ética 278 do cuidado, afirma que:
O mais grave dessa posição parece ser a proposição da identificação com o "sofredor" como única saída alternativa para o modo de produção das psiquiatrias criticadas, inclusive para sua degradação quando os psiquiatras se mostram insuficientes, ou mesmo negligentes, por razões diversas. Parece que essa lógica compassiva é colocada como ética na medida em que também falta a crítica aos modos de produção da Atenção e falta ver que essa "degradação" dos agentes profissionais tem fatores estruturais, decorrentes de sua própria formação como trabalhadores de um campo específico, que se somam aos eventuais fatores pessoais, resultando na soma de cinismo, displicência e mesmo indiferença com que vários deles tratam pessoal e eticamente os sujeitos do sofrimento que se dirigem a eles em busca de ajuda. Embora se escutem perfeitamente nos argumentos de Ferreira (2000) os ecos do discurso psicanalítico, por tomar os discursos apenas como enunciados ideológicos, ele acaba adicionando aos discursos criticados um quarto discurso, cuja diferença dependeria apenas das transformações nos agentes.

Não se trata, portanto, de qualquer tipo de voluntarismo individual, mas a ética do sujeito do [desejo] inconsciente certamente exige dos trabalhadores do campo a superação dialética e coletiva dos modos de produção de saúde e subjetividade em sintonia com o Modo Capitalista de Produção e seus derivados autoritários. "Uma ética do desejo [inconsciente] na Atenção Psicossocial exige que se dê importância radical ao 'instrumental produtivo', ou seja, aos meios de trabalho e aos modos de produção da saúde que essa ética preconiza" (Costa-Rosa, 2011b, p.748). A ética da Atenção Psicossocial, tal como
tem sido proposta pela Reforma Psiquiátrica
e a Reforma Sanitária em alguns de seus
desdobramentos atuais, tem se encaminha-
do para uma modalidade de laço social de
produção de Atenção em que o sujeito - si-
multaneamente considerado como indivíduo 
com inconsciente e como possibilidade de produzir sentido novo para diferentes injunções sociais e subjetivas do cotidiano - deve poder chegar a situar-se no lugar do trabalhador principal do processo da produção dessa Atenção (Costa-Rosa, 2011b, p.750).

Desse modo, as práticas da Atenção Psicossocial estão nos antípodas dos processos de medicalização, de psiquiatrização, de psicologização e de assistencialismo. Ao invés de cuidar de, propõe-se o cuidar-se.

O princípio freudiano do protagonismo do sujeito inclui os aspectos do protagonismo social e coletivo, mas vai além, pondo em destaque um aspecto fundamental do sujeito no sentido psicanalítico, que é o saber inconsciente e o saber sobre o "não sabido" dos coletivos, de mesmo estatuto (Costa-Rosa, 2011b, p.751).

Os discursos fazem laço social (Quinet, 2006), conforme propõe Lacan (1992) no seu Seminário de número 17. Ao avesso da Psicanálise, ele vai atribuir toda a prática que vise agenciar o outro como um objeto que pode ser subjugado, desconsiderando-o como sujeito em sua singularidade desejante. Lacan pretende caracterizar, com sua teoria dos laços discursivos, toda forma de relação social, ou seja, todos os modos de fazer enlace social, toda relação intersubjetiva, constitui-se a partir de quatro discursos possíveis: o Discurso do mestre, o discurso da universidade, o discurso da histeria e o discurso do analista. É a partir dessas complexas referências que Costa-Rosa (2011b) apresenta uma ética singular para a Clínica na Atenção Psicossocial, pautando-se por revoluções discursivas.

No campo múltiplo da Assistência Social, a ética do cuidado emerge claramente do paradigma da Caridade, por meio dos diversos grupos religiosos que empreendem práticas baseadas na ajuda samaritana, de acordo com Benelli e Costa-Rosa (2012). Nesse modelo, a ação institucional se expressa na caridade, nas obras de misericórdia, na ajuda fraterna, na bondade pessoal, no amor ao próximo, na solidariedade, em práticas individuais solidárias, não profissionalizadas, gratuitas, improvisadas e caseiras.
Pode ser situado nessa ética, o trabalho de Zoboli (2004), no campo da enfermagem, e também a eclética perspectiva de Barreto (2011, p.406), que descreve e reflete sobre o que chama de "a dor e a delícia da atuação do psicólogo no SUAS". O autor transita por uma conceituação da "autoetnografia" (p.407), perspectiva centrada no corpo e pertencente ao campo das ciências sociais, mais propriamente da Antropologia pós-estruturalista, e alinha-se com o que denomina de "psicologia engajada", na qual se busca "consolidar uma práxis pautada pelos direitos humanos, na autonomia dos sujeitos e na justiça social" (p.409). Ao propor alguns "elementos que podem contribuir para 0 avanço da atuação profissional e, em consequência, da atenção aos sujeitos da política" (p.410), indica "... o cuidar e ser cuidado, a agressividade e a passividade e escutar o Outro e falar de si". É possível situar esses elementos no plano social comum, no qual os indivíduos se encontram uns com os outros como semelhantes. Ele se localiza plenamente no campo da consciência racional, afetiva e emocional do encontro entre semelhantes.

A noção de cuidado também aparece na literatura numa outra acepção mais politizada e militante, que poderia ser chamada de cuidado psicossocial (Ayres, 2000, 2001, 2004; Macedo \& Dimenstein, 2009, 2011; Murta \& Marinho, 2009; Silveira, \& Vieira, 2005). Diferentemente das modalidades de cuidado também criticadas por Costa-Rosa (2011b), esse subtipo de atuação institucional e ética pretende implementar uma perspectiva que avance de uma posição essencialmente politizante para um trabalho profissional que construa uma "clínica ampliada", de modo a incluir o social e o psíquico em diversas atividades grupais, sobretudo por meio de oficinas que podem incluir objetivos pedagógicos, socializadores e terapêuticos. A clínica seria ampliada a fim de aumentar a variedade dos meios de trabalho (psicoterapia individual, grupo psicoterapêutico, oficinas de socialização e de reconstrução subjetiva, socioterapias, dispositivos de reintegração sociocultural, de trabalho e de geração de renda). Visa-se promover, assim, a reinserção social, ou seja, o aumento da contratualidade social como meio e fim terapêutico. Essa perspectiva é 
forte no âmbito da Saúde Mental Pública (Yasui, 1999, 2010), na perspectiva da ética pública já apresentada no item relativo à ética da ação social.

Situados na ética do cuidado psicossocial, encontra-se na literatura um interessante conjunto de trabalhos que propõem uma forte crítica aos processos disciplinares de normalização social, avançando também para uma clínica ampliada, mas ainda permanecendo - de modo geral -, apenas no plano do sujeito social e histórico (Bastos, \& Rocha, 2011; Bernardes \& Guareschi, 2010; Lemos, 2007; Macerata, 2010; Vasconcelos, 2008). Representativo dessa possibilidade ética do cuidado psicossocial também seria o livro de Cruz e Guareschi (2009), intitulado "Políticas Públicas e Assistência Social: diálogos com as práticas psicológicas". É importante ressaltar que os autores da Filosofia da Diferença, tais como Foucault, Deleuze e Guattari, produziram uma intensa crítica aos processos mistificadores de psicologização, de medicalização, de psiquiatrização e de patologização dos problemas sociais (Guareschi \& Hüning, 2005), o que instrumentalizou os trabalhadores das políticas públicas para promoverem práticas de atuação profissional que se orientem por possibilidades éticas singularizantes, tematizando a questão da produção de subjetividade no contemporâneo (Leite \& Aragão, 2010).

Foucault, por exemplo, também trata das questões do sujeito e da subjetividade e procura demonstrar quais são os modos de sua constituição histórica (Araújo, 2001). Entende-se que ele trata do sujeito social, do "homem" em diferentes modalidades históricas e sociais de existência. Mas ele permaneceria no plano social e histórico em suas análises sobre a subjetividade - tomando o homem como sujeito já constituído -, e não se colocando, por exemplo, a existência de um processo de constituição primária da subjetividade, com suas diversas modalidades e impasses típicos, tais como formulados e formalizados pela psicanálise do campo de Freud e de Lacan. Pode-se considerar que essa perspectiva teórica e ética do cuidado - pautada pela Filosofia da Diferença -, pretenderia superar alguns limites das possibilidades anteriores ao operar com 280 a complexa noção de subjetividade e de processos sócio-históricos de subjetivação. Parece fundamental, entretanto, quando se visa ao homem como sujeito, incluir, além de suas dimensões sociais, históricas, políticas, culturais, também sua característica distintiva, que é ser sujeito de linguagem e de desejo.

\section{A ética do sujeito do desejo inconsciente}

Os processos de constituição da subjetividade - na acepção psicanalítica de realidade psíquica de consistência möebiana -, e seus impasses psíquicos representam uma perspectiva teórica singular. O sujeito não se reduz ao indivíduo e à sua personalidade, conduta, comportamento, razão e sentimento, nem tampouco ao homem como ator social, como cidadão no plano da política, nem ao sujeito do conhecimento como uma unidade racional (Bernandes, 2007). A subjetividade não se limita ao plano psicológico, ao psíquico entendido como interioridade psicológica, nem se esgota no campo social e histórico. Na perspectiva da Psicanálise do campo de Freud e Lacan, ela inclui necessariamente - além desses campos -, o plano do inconsciente, os registros do imaginário, do simbólico e do real, o campo da linguagem, bem como os processos estruturais e lógicos de constituição primária da máquina humana de subjetivar, com seus impasses radicais e as diversas modalizações subjetivas e tipos clínicos deles derivados (Cabas, 2009; Fink, 1998; Garcia-Roza, 2009).

O sujeito do inconsciente se constitui submetido às leis da linguagem (Fink, 1998), possui consistência ética e não ôntica e, como tal, não pode ser protagonista da sua ação, pois ele surge como efeito do ato (da ação, pois). No momento mesmo em que o ato ocorre, o sujeito não está lá. Somente ao se responsabilizar pelo ato que o terá feito surgir, é que ele se implicará como sujeito desse ato. Isso traz, como consequência, que não há sujeito autônomo para a psicanálise. E se o sujeito for o agente em uma relação social, ele estará na posição de exigir do outro seu trabalho e, de certa forma, irá se omitir de sua responsabilidade. Ou seja, de acordo com a ética da psicanálise, o sujeito não é autônomo, nem é agente de suas ações. Ele é sujeito e 
tem, paradoxalmente, que se responsabilizar ali mesmo onde está sujeito à palavra que lhe é imposta para daí transformá-la, fazê-la valer, orientado pela ética do desejo inconsciente. Aliás, desejo inconsciente que já aponta para o desejo de um sujeito determinado para além de sua vontade, de seu querer intencional e consciente.

Parte-se do princípio de que as práticas, ações e relações socioassistenciais implementadas de acordo com uma Pedagogia, com uma Psicologia e com uma prática político-social tradicionais, verticais e autoritárias, alinhadas com os interesses da classe dominante, são reprodutoras dos sentidos sociais dominantes, por meio de práticas objetificadoras que mantêm o sujeito (criança, adolescente, jovem, adulto, idoso) alienado quanto aos possíveis fundamentos da sua condição de cidadão que tem seus direitos sistematicamente violados pela (des)ordem institucionalizada - dos quais não tem sequer consciência e normalmente nem se queixa - e, sobretudo, quanto ao seu posicionamento com relação aos determinantes que incidem nas suas condições existenciais.

Como dar suporte para que as práticas dos profissionais da psicologia que atuam na Assistência Social sejam atravessadas, minimamente, pela ética do sujeito? Desde logo, não se trata de uma ética individual, dependente exclusivamente das condições de formação dos psicólogos no campo epistemológico da Psicologia. Embora o psicólogo possa, durante sua formação, ter notícias e, inclusive, um conhecimento introdutório sobre a Psicanálise, a ética do sujeito do desejo aponta, justamente, para outras direções. A Psicanálise constitui um campo epistemológico, teórico e metodológico específico no qual sua enunciação se torna possível. Ao se propor uma ética do sujeito, é preciso apontar quais são os dispositivos necessários, sobretudo os de formação - que incluem o estudo e a apropriação teórica da psicanálise, a experiência pessoal de análise e a supervisão de atendimentos clínicos -, para que seja plausível orientar as práticas dos psicólogos no campo da Assistência Social, sob a inspiração da psicanálise lacaniana, numa modalidade de atuação profissional que se paute pela escuta clínica analítica, que tanto pode ser indivi- dual, grupal ou institucional. Pontua-se que o âmbito institucional é uma dimensão muito importante do trabalho do psicólogo avisado e precavido pela psicanálise. Fundamental aqui é a distinção que se faz entre psicanálise em intensão e psicanálise em extensão (Miller, 2001; Ribeiro, 2007). Nesse sentido, postula-se também a necessidade de certa ampliação da "psicanálise em intensão" (Lima \& Altoé, 2005), visando a um trabalho de intercessão no plano institucional propriamente dito (Altoé, 2004).

Como trabalharia o psicólogo avisado e precavido pela Psicanálise do campo de Freud e Lacan no âmbito da Assistência Social? Há pelo menos três questões básicas a serem consideradas quanto à orientação das práticas institucionais: a perspectiva teórico-técnica quanto aos processos de constituição da subjetividade e seus impasses psíquicos; a posição ética do trabalhador com relação às possíveis modalidades de produção de subjetividade; subjetividade serializada e singularizada, e também as formas de oferta transferencial. Por exemplo, Mariano (2011) discute e comprova a possibilidade de se escutar o sujeito do inconsciente no Centro de Referência da Assistência Social (CRAS), apresentando a proposta de que realizar uma intervenção retificadora terapêutica pode caracterizar o trabalho do praticante de psicanálise inserido nesse tipo de serviço. Tal intervenção serve apenas como uma proposta de atendimento para os casos em que se apresente uma demanda de caráter subjetivo. Ele relata um caso de atendimento realizado no CRAS de uma cidade de Minas Gerais em que a intervenção tornou possível uma mudança na posição subjetiva do sujeito em questão. Além disso, talvez a "clínica da urgência" (Barreto, 2004; Calazans \& Bastos, 2008) pudesse funcionar como uma fonte de inspiração norteadora para uma intercessão social clínica no âmbito da Assistência Social. Essa variação clínica procura reintroduzir a experiência da escuta analítica, articulando-a com o enquadramento das entrevistas preliminares (Golder, 2000; Quinet, 2000) nas quais Jacques Lacan recupera, a partir de Freud, a importância dos primeiros encontros para a construção e a direção do tratamento, como um dispositivo para 
interceder em momentos específicos nos quais o sujeito, premido pelo insuportável do seu sofrimento, procura ajuda.

Quanto às modalidades de produção de subjetividade, é preciso distinguir entre a subjetividade serializada (adaptada, ajustada, subordinada, submetida, alienada) e a subjetividade singularizada (desejante, criativa, transformadora, crítica, autoanalítica, autogestiva). As formas de oferta transferencial incluem três possibilidades: a) oferta de um objeto, tais como cestas de alimentos, remédios, benefícios financeiros diversos, bolsas; b) oferta de um saber de mestria pedagógico/educativa - ou socioeducativa -, que dialoga e terapeutiza, cuida e tutela, informa e orienta, julga e aconselha, moraliza e normaliza a conduta do outro; c) oferta de uma escuta do sujeito do desejo inconsciente, como pos-tula a psicanálise de Freud e Lacan. Não se trata necessariamente de promover um processo tera-pêutico analítico no âmbito da Assistência Social, mas de estar orientado pela ética do sujeito (Kehl, 2002; Lacan, 1997).

A opção tomada é por uma ética singularizante nas práticas de assistência psicológica. De acordo com Costa-Rosa (2000), sujeito singularizado é aquele capaz de implicação subjetiva, que se refere à capacidade de posicionar-se ativamente em relação a conflitos e a contradições. Movido por sua capacidade desejante e de autodeterminação, o sujeito não apenas sofre os efeitos de tais conflitos e contradições de modo que fiquem intactos na sua reprodução, mas posiciona-se de forma a trabalhar na direção de sua metabolização e superação. Através da capacidade constante de mutabilidade, vai-se autoproduzindo e produzindo o mundo em que habita. Um indivíduo capaz de implicação subjetiva e sociocultural caracteriza-se por uma subjetividade singularizada: ele posiciona-se como um sujeito diante dos conflitos e contradições do próprio desejo e de suas conexões com a realidade social mais ampla, sendo capaz de uma vida produtiva (Costa-Rosa, 2000). Seu contraponto é a subjetividade serializada: o indivíduo se reconhece

282 apenas nas imagens identitárias oferecidas pelo mercado, imagens essas que consome, reproduz e com relação às quais se posiciona como uma vítima impotente e sem implicação nos problemas dos quais se queixa.

Há alguns autores relevantes na discussão acerca da "ética do sujeito" implicada nas práticas profissionais no campo pedagógico e educativo, pautadas pela perspectiva da psicanálise, como Imbert (2002) e Mireille Cifali (Cifali \& Imbert, 1999). Eles são fonte de inspiração para vários autores brasileiros que se dedicam a introduzir a ética do desejo no campo clínico-educativo, tais como Almeida e Kupfer (2011), Amparo, Almeida, Brasil, Conceição e Marty (2012), Kupfer (2007), Lajonquière (1999; 2010), Pereira (2003; 2008; 2012), Santos (2011), Voltolini (2011), dentre outros. Ainda não são muitos os trabalhos que tratam do sujeito a partir da conceituação da psicanálise do campo de Freud e de Lacan no âmbito da Assistência Social (Altoé, 2004; Ferreira, 2001; Lima \& Altoé, 2005; Mariano, 2011; Rogone, 2006; Scarparo \& Poli, 2008; Susin, 2012); eles são mais abundantes no campo da Saúde Mental (Alberti \& Elia, 2000; Alberti \& Figueiredo, 2006; Costa-Rosa, 2000, 2011a, 2011b; Dassoler \& Palma, 2012; Rinaldi, 1996). Desde logo, não se trata de acrescentar mais uma modalidade terapêutica, dentre outras pos-síveis, ao arsenal do psicólogo que atua nesse campo institucional. O critério fundamental é a radicalidade ética e uma rigorosa lógica conceitual, com seus desdobramentos técnicos e políticos. Nesse sentido, pode ser encontrada em Costa-Rosa (2011b) uma ética e uma clínica singulares para a Atenção Psicossocial, fundamentadas em contribuições da Psicanálise do campo de Freud e Lacan. Essa modalidade ética poderia ser denominada como ética do sujeito, incluindo tanto o homem como ator social no plano da política e da história, quanto o sujeito (do desejo) inconsciente, compreendidas suas especificidades. Não é aceitável, na Atenção Psicossocial, que as práticas da Assistência Social promovam formas de subjetividade alienada, pois esse é um aspecto fundamental que uma ética radicalmente cidadã deve questionar e buscar superar. 


\section{Conclusão}

Partiu-se da hipótese de que a ética pode ser tomada como um bom parâmetro analítico das práticas institucionais de atenção psicológica na Assistência Social. Tomando como base uma ampla revisão da literatura e se sustentando na própria experiência clínico-institucional, construiu-se uma tipologia de modalidades de atenção psicológica e de atuação institucional. A perspectiva ética da Atenção Psicossocial, de modo congruente, obriga a encararem-se resolutamente as formas atuais que configuram a atenção assistencial desenvolvidas no âmbito da Assistência Social como política de Estado, buscando interpelar os atores sociais encarregados desses serviços nos vários contextos institucionais. A luta pelos direitos de cidadania e também pela posição de sujeito desejante da população que utiliza tais programas, projetos e serviços pode e deve ser, hoje, um esforço visando à transformação da realidade institucional e social, que se limita, muitas vezes, quase que somente a gerenciar os "riscos" aos quais os pobres e seus filhos estão sujeitos.

A discussão apresentada não deixa de ser provocadora e nela há certamente um tom de denúncia, mas a análise apresentada foi clara e rigorosamente determinada pelas exigências teóricas, metodológicas e éticas da perspectiva institucionalista adotada, longe de qualquer intenção panfletária e irresponsável. Para além da pretensão de dar conta de certa "objetividade empirista", o que se buscou foi, de modo coerente com a Análise Institucional, a partir do material disponível, apreender a processualidade do fenômeno em seus aspectos dinâmicos, essenciais e estruturais.

\section{Referências}

Abreu Filho, O. (1996). Ética: um ensaio sobre a consciência do mal. Mana, 2(2), 189-191.

Aguiar, K. F., \& Rocha, M. L. (2007). Micropolítica e o exercício da pesquisa-intervenção: referenciais e dispositivos em análise. Psicologia, Ciência e Profissão, 27(4), 648-663.

Alberti, S., \& Elia, L. (2000). Clínica e pesquisa em psicanálise. Rio de Janeiro: Rios Ambiciosos.
Alberti, S., \& Figueiredo, A. C. (Orgs.). (2006). Psicanálise e saúde mental: uma aposta. Rio de Janeiro: Companhia de Freud.

Almeida, S. F. C., \& Kupfer, M. C. M. (Orgs.). (2011). A psicanálise e o trabalho com a criança-sujeito: no avesso do especialista. Rio de Janeiro: Wak.

Altoé, S. (2004). A psicanálise pode ser de algum interesse no trabalho institucional com crianças e adolescentes? In S. Altoé. Sujeito do direito, sujeito do desejo: direito e psicanálise (pp.51-60). Rio de Janeiro: Revinter.

Alves, A. M. (2010). O método materialista histórico dialético: alguns apontamentos sobre a subjetividade. Revista de Psicologia da UNESP, 9(1), 1-13.

Amparo, D. M., Almeida, S. F. C., Brasil, K. C. T. R., Conceição, M. I. G., \& Marty, F. (Orgs.). (2012). Adolescência e violência: intervenções e estudos clínicos, psicossociais e educacionais. Brasília: Universidade de Brasilia.

Araújo, I. L. (2001). Foucault e a crítica do sujeito. Curitiba: UFPR.

Araújo, F. I. C. (2010). "Mas a gente não sabe que roupa a gente deve usar...": um estudo sobre a prática do psicólogo no Centro de Referência da Assistência (CRAS) (Dissertação de mestrado não-publicada). Pontifícia Universidade Católica de São Paulo.

Ayres J. R. C. M. (2000). Cuidado: tecnologia ou sabedoria prática? Interface: Comunicação, Saúde e Educação, 6(1), 117-20.

Ayres, J. R. C. M. (2001). Sujeito, intersubjetividade e práticas de saúde. Ciência \& Saúde Coletiva, 7(1), 63-72.

Ayres, J. R. C. M. (2004). Cuidado e reconstrução das práticas de saúde. Interface: Comunicação, Saúde e Educação, 8(14), 73-92.

Baratto, G., \& Aguiar, F. (2007). A "psicologia do ego" e a psicanálise freudiana: das diferenças teóricas fundamentais. Revista de Filosofia: Aurora, 19(25), 307-331.

Baremblitt, G. F. (1998). Compêndio de análise institucional e outras correntes: teoria e prática. Rio de Janeiro: Record.

Barreto, A. F. (2011). Sobre a dor e a delícia da atuação do psicólogo no SUAS. Psicologia, Ciência e Profissão, 31(2), 406-419.

Barreto, F. P. (2004). A urgência subjetiva na saúde mental: opção lacaniana. Revista Brasileira Internacional de Psicanálise, 40(1), 47-51.

Barus-Michel, J. (2004). O sujeito social. Belo Horizonte: Puc Minas.

Bastos, C. P. S., \& Rocha, M. L. (2011). Territórios em comum nas políticas públicas: psicologia e assistência social. Psicologia \& Sociedade, 23(3), 634-636.

Benelli, S. J. (2009). A cultura psicológica no mercado de bens de saúde mental contemporâneo. Estudos de 
Psicologia (Campinas), 26(4), 515-536. doi: 10.1590/S0 103-166X2009000400012

Benelli, S. J. (2012). Pistas pedagógicas para a socioeducação de crianças e adolescentes na entidade assistencial. In O. C. Mattioli, M. F. Araújo \& V. R. Resende (Orgs.), Família, violência e politicas públicas: pesquisas e práticas (pp.59-87). Assis: Unesp.

Benelli, S. J., \& Costa-Rosa, A. (2003). Geografia do poder em Goffman: vigilância e resistência, dominação e produção de subjetividade no hospital psiquiátrico. Estudos de Psicologia (Campinas), 20(2), 35-49. doi: 10.1590/S0103-166X2003000200004

Benelli, S. J., \& Costa-Rosa, A. (2011). Para uma crítica da razão socioeducativa em entidades assistenciais. Estudos de Psicologia (Campinas), 28(4), 539-563. doi: 10.1590/S0103-166X2011000400014

Benelli, S. J., \& Costa-Rosa, A. (2012). Paradigmas diversos no campo da Assistência Social e seus estabelecimentos assistenciais típicos. Psicologia USP, 23(4), 609-660.

Benelli, S. J., \& Costa-Rosa, A. (2013). Dispositivos institucionais filantrópicos e socioeducativos de atenção à infância na Assistência Social. Estudos de Psicologia (Campinas), 30(2), 283-301. doi: 10.1590/S0103-166X 2013000200015

Bernardes, A. G., \& Guareschi, N. M. F. (2010). Práticas psicológicas: enfrentamentos entre saúde pública e saúde coletiva. Estudos de Psicologia, 15(3), 269-276.

Bernardes, L. H. G. (2007). Subjetividade: um objeto para uma psicologia comprometida com o social. São Paulo: Casa do Psicólogo.

Bock, A. M. B., Gonçalves, M. G., \& Furtado O. (Orgs.). (2002). Psicologia sócio-histórica: uma perspectiva crítica em psicologia. São Paulo: Cortez.

Brasil. Casa Civil. (1988). Constituição da República Federativa do Brasil. Brasília: Casa Civil. Recuperado em maio 5, 2011, de www.planalto. gov.br/ccivil_03/ Constituicao/constitui\%C3\%A7ao_compilado.ht

Brasil. Ministério do Desenvolvimento Social e Combate a Fome. (1993). Lei n 8.742, de 7 dezembro de 1993. Dispõe sobre organização e da outras providencias. Brasília: Diário Oficial da União. Recuperado em janeiro 5, 2011, de http://www.mds.gov.br/cnas/legislacao/leis

Brasil. Ministério do Desenvolvimento Social e Combate a Fome. (2004). Política nacional de assistência social. Brasília: Ministério do Desenvolvimento Social e Combate a Fome. Recuperado em março 10, 2008, de http://www.mds.gov.br/cnas/legislacao/leis

Brasil. Ministério do Desenvolvimento Social e Combate a Fome. (2005). Norma operacional básica do sistema único de assistência social. Brasília: Ministério do Desenvolvimento Social e Combate a Fome. Recuperado em março 10, 2008, de http://www.mds.gov.
Brasil. Ministério do Desenvolvimento Social e Combate a Fome. (2011). Lei $n^{\circ} 12.435$ de 6 de julho de 2011. Altera a Lei $n^{\circ}$ 8.742, de 7 dezembro de 1993, que Dispõe sobre organização e da outras providencias. Brasília: Ministério do Desenvolvimento Social e Combate a Fome. Recuperado em julho 30, 2011, de http:// www.mds.gov.br/cnas/legislacao/leis

Brasil. Ministério do Desenvolvimento Social e Combate a Fome. (2012). Norma Operacional Básica da Assistência Social - NOB/SUAS. Brasília: Ministério do Desenvolvimento Social e Combate a Fome. Recuperado em dezembro 13, 2012, de http:// www.mds. gov.br/cnas/politica-e-nobs

Cabas, A. G. (2009). O sujeito na psicanálise de Freud a Lacan: da questão do sujeito ao sujeito em questão. Rio de Janeiro: Zahar.

Calazans, R., \& Bastos, A. (2008). Urgência subjetiva e clínica psicanalítica. Revista Latino-americana de Psicopatologia Fundamental, 11(4), 640-652.

Castro, F. G. (2009). Materialismo histórico e definição de psíquico. Psicologia \& Sociedade, 21(2), 182-192.

Cifali, M., \& Imbert, F. (1999). Freud e a pedagogia. São Paulo: Loyola.

Clavreul, J. (1983). A ordem médica: poder e impotência do discurso médico. São Paulo: Brasiliense.

Coll, C., Marchesi, A., \& Palácios, J. (2004). Desenvolvimento psicológico e educação. Porto Alegre: Artes Médicas.

Conselho Nacional de Assistência Social. (2009). Caderno de textos: participação e controle social no SUAS. Brasília: Autor.

Conselho Nacional de Assistência Social. (2011). Caderno de textos: consolidar o SUAS e valorizar seus trabalhadores. Brasília: Autor.

Costa, A. F. S., \& Cardoso, C. L. (2010). Inserção do psicólogo em Centros de Referência de Assistência Social - CRAS. Gerais: Revista Interinstitucional de Psicologia, 3(2), 223-229.

Costa-Rosa, A. (2000). O modo psicossocial: um paradigma das práticas substitutivas ao modo asilar. In P. D. C. Amarante (Org.), Ensaios de loucura \& civilização (pp.141-168). Rio de Janeiro: Fiocruz.

Costa-Rosa, A. (2011a). Operadores fundamentais da atenção psicossocial: contribuição a uma clínica crítica dos processos de subjetivação na saúde coletiva (Tese de livre-docência não-publicada). Universidade Estadual Paulista Júlio de Mesquita Filho, Assis.

Costa-Rosa, A. (2011b). Ética e clínica na atenção psicossocial: contribuições da psicanálise de Freud e Lacan. Saúde e Sociedade, 20(3), 743-757.

Cotrim, G. (1993). Educação para uma escola democrática: história e filosofia da Educação. São Paulo: Saraiva. 
Crepop. (2008). Referências técnicas para atuação do(a) psicólogo(a) no CRAS/SUAS. Brasília: Conselho Federal de Psicologia.

Cruz, J. M. O. (2009). Práticas psicológicas em Centros de Referência da Assistência Social (CRAS). Psicologia em Foco, 2(1), 11-27.

Cruz, L. R., \& Guareschi, N. (Orgs.). (2009). Políticas públicas e assistência social: diálogos com as práticas psicológicas. Petrópolis: Vozes.

Dadico, L., \& Souza, M. P. R. (2010). Atuação do psicólogo em organizações não-governamentais na área da educação. Psicologia, Ciência e Profissão, 30(1), 114-131.

Dassoler, V. A., \& Palma, C. M. S. (2012). A dimensão da ética nas intervenções do analista frente às demandas institucionais dos CAPS. Revista Latinoamericana de Psicopatologia Fundamental, 15(1), 94-107.

Demo, P. (1987). Introdução à metodologia da ciência. São Paulo: Atlas.

Depraz, N. (2005). A ética relacional: uma prática de ressonância interpessoal. Revista do Departamento de Psicologia, 17(2), 19-34.

Eidelwein, K. (2007). Psicologia Social e Serviço Social: uma relação interdisciplinar na direção da produção de conhecimento. Textos \& Contextos, 6(2), 298-313

Ferreira, A. P. (2000). Ação e reflexão no campo dos cuidados. In S. Alberti \& L. Elia (Orgs.), Clínica e pesquisa em Psicanálise (pp.145-154). Rio de Janeiro: Rios Ambiciosos.

Ferreira, T. M. B. C. (2001). Os meninos e a rua: uma interpelação à psicanálise. Belo Horizonte: Autêntica.

Fink, B. (1998). O sujeito lacaniano: entre a linguagem e o gozo. Rio de Janeiro: Zahar.

Fleming, M. (1976). Ideologia e práticas psiquiátricas. Porto: Afrontamento.

Foucault, M. (1995). O sujeito e o poder. In P. Rabinow \& H. Dreyfus. Michel Foucault, uma trajetória filosófica: para além do estruturalismo e da hermenêutica (pp.231-249). Rio de Janeiro: Forense.

Foucault, M. (1999). Vigiar e punir: nascimento da prisão. Petrópolis: Vozes.

Francisco Filho, G. (2004). Panorâmica das tendências e práticas pedagógicas. Campinas: Átomo.

Freire Costa, J. (1996). As éticas da psiquiatria. In A. C. Figueiredo \& J. F. Silva (Orgs.), Ética e saúde mental (pp.27-36). Rio de Janeiro: Topbooks.

Furtado, O., \& Rey, F. G. (2002). Por uma epistemologia da subjetividade: um debate entre a teoria sócio-histórica e a teoria das representações sociais. São Paulo: Casa do Psicólogo.

Gallio, G., \& Constantino, M. (1993). François Tosquelles: a escola de liberdade. In A. Lancetti. Saúde e loucura, 4 (Vol. 4, pp.85-128). Säo Paulo: Hucitec.

Garcia-Roza, L. A. (2009). Freud e o inconsciente. Rio de Janeiro: Zahar.
Goffman, E. (1987). Manicômios, prisões e conventos. São Paulo: Perspectiva.

Golder, E. M. (2000). Clínica da primeira entrevista. Rio de Janeiro: Zahar.

Gonçalves, M. G. M. (2010). Psicologia, subjetividade e políticas públicas. São Paulo: Cortez.

Gondar, J. (2004). Ética, moral e sujeito. In S. Altoé. Sujeito de direito, sujeito de desejo: direito e psicanálise (pp.29-38). Rio de Janeiro: Revinter.

Guareschi, N. M. F., \& Hüning, S. M. (Orgs.). (2005). Foucault e a psicologia. Porto Alegre: Abrapso Sul.

Hurtado, C. N. (1992). Educar para transformar, transformar para educar: comunicação e educação popular. Petrópolis: Vozes.

Imbert, F. (2002). A questão da ética no campo educativo. Petrópolis: Vozes.

Julien, P. (1996). O estranho gozo do próximo: ética e psicanálise. Rio de Janeiro: Zahar.

Kehl, M. R. (2002). Sobre ética e psicanálise. São Paulo: Companhia das Letras, 2002.

Kupfer, M. C. M. (2007). Educação para o futuro: educação e psicanálise. São Paulo: Escuta.

Lacan, J. (1992). O seminário, livro 17: o avesso da psicanálise [1969-70]. Rio de Janeiro: Zahar.

Lacan, J. (1997). O seminário, livro 7: a ética em psicanálise. Rio de Janeiro: Zahar.

Lajonquière, L. (1999). Infância e ilusão (psico)pedagógica: escritos de psicanálise e educação. Petrópolis: Vozes.

Lajonquière, L. (2010). Figuras do infantil: a psicanálise na vida cotidiana com as crianças. Petrópolis: Vozes.

Leite, L., \& Aragão, E. M. A. (2010). O exercício ético na constituição do sujeito político como cidadão. Fractal, Revista de Psicologia, 22(3), 543-556.

Lemos, F. C. S. (2007). Crianças e adolescentes entre a norma e lei: uma análise foucaultiana (Tese de doutorado não-publicada). Universidade Estadual Paulista Júlio de Mesquita Filho, Assis.

Libaneo, J. C. (1994). Tendências pedagógicas na prática escolar. In C. C. Luckesi. Filosofia da educação (pp.53-74). São Paulo: Cortez.

Lima, M. J., \& Cerveny, C. M. O. (2012). A competência social do Psicólogo: estudo com profissionais que atuam em instituições. Psicologia, Ciência e Profissão, 32(2), 284-303.

Lima, M. M., \& Altoé, S. (Orgs.). (2005). Psicanálise, clínica e instituição. Rio de Janeiro: Rios Ambiciosos.

Lourau, R. (1995). A análise institucional. Petrópolis: Vozes.

Macedo, J. P., \& Dimenstein, M. (2009). Psicologia e a produção do cuidado no campo do bem-estar social. Psicologia e Sociedade, 21(3), 293-300. 
Macedo, J. P., \& Dimenstein, M. (2011). Expansão e interiorização da Psicologia: reorganização dos saberes e poderes na atualidade. Psicologia: Ciência e Profissão, 31(2), 296-313.

Macerata, I. M. (2010). “... como bruxos maneando ferozes": relações de cuidado e de controle no fio da navalha: experiência "psi" em dispositivo da política de assistência social para crianças e adolescentes em situação de rua (Dissertação de mestrado não-publicada). Universidade Federal Fluminense, Niterói.

Mariano, M. L. H. S. (2011). Psicanálise e cidadania: uma intervenção do praticante de psicanálise no Centro de Referência da Assistência Social (CRAS) e outras questões. Curitiba: CRV.

Martins, J. B. (Org.). (2002). Temas em análise institucional e em construcionismo social. São Carlos: Rima.

Mauriel, A. P. O. (2010). Pobreza, seguridade e assistência social: desafios da política social brasileira. Katálysis, 13(2), 173-180.

Merhy, E. E. (1998). A perda da dimensão cuidadora na produção da Saúde: uma discussão do modelo assistencial e da intervenção no seu modo de trabalhar a assistência. In C. R., Campos. Sistema Único de Saúde em Belo Horizonte: reescrevendo o público (pp.103-120). São Paulo: Xamã.

Miller, J. A. (2001). Psicanálise pura, psicanálise aplicada e psicoterapia. Phoenix, 3(3), 9-44.

Murta, S. G., \& Marinho, T. P. C. M. (2009). A clínica ampliada e as políticas de assistência social: uma experiência com adolescentes no programa de atenção integral à família. Revista Eletrônica de Psicologia e Políticas Públicas, 1(1), 58-72.

Oliveira, I. F., Dantas, C. M. B., Solon, A. F. A. C., \& Amorim, K. M. O. (2011). A prática psicológica na proteção social básica do SUAS. Psicologia \& Sociedade, 23(Esp.), 140-149.

Oury, J. (2009). O coletivo. São Paulo: Hucitec.

Paiva, B., Rocha, M., \& Carraro, D. (2010). Participação popular e assistência social: contraditória dimensão de um especial direito. Katálysis, 13(2), 250-259.

Paiva, I. L., \& Yamamoto, O. H. (2010). Formação e prática comunitária do psicólogo no âmbito do "terceiro setor". Estudos de Psicologia (Natal), 15(2), 153-160.

Patto, M. H. S. (1997). Para uma crítica da razão psicométrica. Psicologia USP, 8(1), 47-62.

Pereira, M. R. (2003). O avesso do modelo: bons professores e a psicanálise. Petrópolis: Vozes.

Pereira, M. R. (2008). A impostura do mestre. Belo Horizonte: Fino Traço.

Pereira, M. R. (2012). A psicanálise escuta a educação: 10 anos depois. Belo Horizonte: Fino Traço.

Quinet, A. (2000). As $4+1$ condições da análise. Rio de Janeiro: Zahar.
Quinet, A. (2006). Psicose e laço social: esquizofrenia, paranóia e melancolia. Rio de Janeiro: Zahar.

Rey, F. G. (2003). Sujeito e subjetividade: uma aproximação histórico-cultural. São Paulo: Pioneira Thomson Learning.

Rey, F. G. (2004). O social na psicologia e a psicologia social: a emergência do sujeito. Rio de Janeiro: Vozes.

Ribeiro, V. A. (2007). Pertinências da psicanálise aplicada: trabalhos da Escola da Causa Freudiana reunidos pela Associação do Campo Freudiano. Rio de Janeiro: Forense.

Rinaldi, D. (1996). Ética da diferença. Rio de Janeiro: Zahar.

Rinaldi, D. (2006). Entre o sujeito e o cidadão: psicanálise ou psicoterapia no campo da saúde mental? In S. Alberti \& A. C. Figueiredo (Orgs.), Psicanálise e saúde mental: uma aposta (pp.141-147). Rio de Janeiro: Companhia de Freud.

Rogone, H. M. H. (2006). Psicanálise e cidadania: correndo riscos e tecendo laços (Tese de doutorado não-publicada). Universidade de São Paulo.

Rosas, P. S. (2010). O dilema da psicologia contemporânea. Psicologia, Ciência e Profissão, 30(Esp.), 42-90.

Rotelli, F. (1994). Desinstitucionalização. São Paulo: Hucitec.

Santos, B. S. (2000). A crítica da razão indolente: contra o disperdício da experiência. São Paulo: Cortez.

Santos, L. P. (2011). Implicações do campo da psicanálise para a prática educativa no cotidiano escolar (Dissertação de mestrado não-publicada). Universidade Federal de Goiás, Goiânia.

Saviani, D. (1988). Escola e democracia: teorias da educação, curvatura da vara, onze teses sobre educação e política. São Paulo: Cortez.

Scarparo, M. L. D-E., \& Poli, M. C. (2008). Psicanálise e assistência social. Barbarói, 28(1), 50-74.

Senra, C. M. G., \& Guzzo, R. S. L. (2012). Assistência social e psicologia: sobre as tensões e conflitos do psicólogo no cotidiano do serviço público. Psicologia \& Sociedade, 24(2), 293-299.

Silva, J. V., \& Corgozinho, J. P. (2011). A atuação do psicólogo, SUAS/CRAS e psicologia social comunitária: possíveis articulações. Psicologia \& Sociedade, 23(Esp.), 12-21.

Silveira, D. P., \& Vieira, A. L. S. (2005). Reflexões sobre a ética do cuidado em saúde: desafios para a atenção psicossocial no Brasil. Estudos e Pesquisas em Psicologia, 5(1), 92-101.

Souza, R. A., \& Prado Filho, K. (2008). Cidadania: discurso da valoração da sociedade e práticas de valorização da vida. Revista de Psicologia da UNESP, 7(1), 169-175. 
Susin, L. M. (2012). O mal-estar na cultura e suas incidências na clínica em contextos de exclusão (Dissertação de mestrado não-publicada). Universidade Federal do Rio Grande do Sul, Porto Alegre.

Vallejo, A., \& Magalhães, L. C. (1979). Lacan: operadores de leitura. São Paulo: Perspectiva.

Vasconcelos, E. M. (2008). Abordagens psicossociais: história, teoria e trabalho no campo (Vol. 1). São Paulo: Hucitec.

Voltolini, R. (2011). Educação e psicanálise. Rio de Janeiro: Zahar.

Ximenes, V. M., Paula, L. R. C., \& Barros, J. P. P. (2009). Psicologia comunitária e política de assistência social: diálogos sobre atuações em comunidades. Psicologia: Ciência e Profissão, 29(4), 686-699.
Yamamoto, O. H., \& Oliveira, I. F. (2010). Política Social e Psicologia: uma trajetória de 25 anos. Psicologia: Teoria e Pesquisa, 26(Esp.), 9-24.

Yasui, S. (1999). A construção da Reforma Psiquiátrica e seu contexto histórico (Dissertação de mestrado não-publicada). Universidade Estadual Paulista Júlio de Mesquita Filho, Assis.

Yasui, S. (2010). Rupturas e encontros: desafios da Reforma Psiquiátrica brasileira. Rio de Janeiro: Fiocruz.

Zoboli, E. L. C. P. (2004). A redescoberta da ética do cuidado: o foco e a ênfase nas relações. Escola de Enfermagem USP, 38(1), 21-7.

Recebido em: 7/12/2012

Versão final em: 27/6/2013

Aprovado em: 6/9/2013 
